\title{
SMALL INFANT CONTACTS OF FINNISH MEDICAL STUDENTS BEFORE THEIR CLINICAL PEDIATRIC COURSE
}

M. Valkama, M. Mäkelä

\author{
Pediatrics and Adolescence, Oulu University Hospital, Oulu, Finland
}

In order to evaluate small infant experiences of medical students before their pediatric course a questionnaire was made in Oulu University Hospital.

227 out of the $241(94,2 \%)$ medical students participating clinical pediatric courses between the autumn 2004 and 2006 fulfilled questionnaire forms about their experiences. 32,6\% of students were male and 67,0 $\%$ female, and one $(0,4 \%)$ unknown. $7,5 \%$ of the answered students were the only offspring in their native families. The rest $96,5 \%$ had one to 14 siblings. 18 students had own children.

Five students had never kept an infant in lap. 86(37,9\%) had never fed infants, 22(9,7 \%) had given bottle feeding, and 117(51,5\%) of the students had given solid food.

$4,4 \%$ of the students hadn't dared to touch infants. $6,6 \%$ felt it frightening to handle infants, and $40,1 \%$ marked to feel tense to handle infants. $140(61,7 \%)$ thought they can manage with infants, and furthermore $58,6 \%$ gave voice to waiting for permission to handle infants. Only $11,9 \%$ acknowledged to be quite familiar with handling infants. 22,9\% had cared for their infant siblings, and 20,7\% had been working occasionally as a babysitter.

Almost all students had worked as a doctor before clinical pediatric courses. If they have had to care infants, they had felt themselves sensitive and careful, used self-studying and supervising possibilities. Almost a half of the students had consulted pediatricians. 